Article

\title{
Fire Retardancy, Water Absorption, and Viscoelasticity of Borated Wood-Polycarbonate Biocomposites
}

\author{
Jingfa Zhang ${ }^{1,2}$, Ahmed Koubaa ${ }^{1, *(\mathbb{D})}$, Dan Xing ${ }^{1, *}$, François Godard ${ }^{1}$, Peng Li $^{2}$, Yubo Tao ${ }^{2}$, Xiang-Ming Wang ${ }^{3}$ \\ and Haigang Wang 4 (D) \\ 1 Laboratoire de Biomatériaux, Université du Québec en Abitibi-Témiscamingue, \\ Rouyn-Noranda, QC J9X 5E4, Canada; zjf2010d1@126.com (J.Z.); Francois.Godard@uqat.ca (F.G.) \\ 2 State Key Laboratory of Biobased Material and Green Papermaking, Qilu University of Technology, \\ Shandong Academy of Sciences, Jinan 250353, China; lipeng@qlu.edu.cn (P.L.); taoyubo@qlu.edu.cn (Y.T.) \\ 3 New Construction Materials Group, FPInnovations, Québec, QC G1V 4C7, Canada; Wang@fpinnovations.ca \\ 4 Key Laboratory of Bio-Based Materials Science and Technology (Ministry of Education), \\ Northeast Forestry University, Harbin 150040, China; hgwang@nefu.edu.cn \\ * Correspondence: Ahmed.Koubaa@uqat.ca (A.K.); Dan.Xing@uqat.ca (D.X.)
}

check for updates

Citation: Zhang, J.; Koubaa, A.; Xing, D.; Godard, F.; Li, P.; Tao, Y.; Wang, X.-M.; Wang, H. Fire Retardancy, Water Absorption, and Viscoelasticity of Borated Wood-Polycarbonate Biocomposites. Polymers 2021, 13 , 2234. https://doi.org/10.3390/ polym13142234

Academic Editors:

Łukasz Klapiszewski and

Antonio Zuorro

Received: 25 May 2021

Accepted: 29 June 2021

Published: 7 July 2021

Publisher's Note: MDPI stays neutral with regard to jurisdictional claims in published maps and institutional affiliations.

Copyright: (c) 2021 by the authors. Licensee MDPI, Basel, Switzerland. This article is an open access article distributed under the terms and conditions of the Creative Commons Attribution (CC BY) license (https:/ / creativecommons.org/licenses/by/ $4.0 /)$.

\begin{abstract}
Demand for high-performance biocomposites is increasing due to their ease of processing, low environmental impact, and in-service performance. This study investigated the effect of boric acid modification of wood flour on polycarbonate (PC) wood composites' thermal stability, fire retardancy, water absorption, and creep behavior. The composites' fire retardancy increased with increasing wood flour content, and their char residue increased by $102.3 \%$ compared to that of pure PC. However, the water absorption of the resulting composites increased due to the hydroxyl groups of the wood flour. Wood flour also improved the composites' anti-creep properties. The excellent fire retardancy and anti-creep properties of wood-PC composites expand their use in the construction sector.
\end{abstract}

Keywords: polycarbonate; boric-acid treatment; wood flour; biocomposites; fire retardancy; dimensional stability; creep behavior

\section{Introduction}

Nowadays, wood-polymer composites (WPCs) as a potential material have captured both researchers' and manufacturers' attention due to their advanced characteristics, such as rot resistance, durability, low cost, dimensional stability, high stiffness, and strength [1-3]. They are widely used in buildings, decoration, transport, furniture, and decking areas [4]. WPC is expanding rapidly since its emergence, and its production is increasing [5]. However, both lignocellulose and polyolefin are flammable. Hence, improving the fire retardancy of biocomposites to expand their utilization to other sectors.

Ammonium polyphosphate (APP) [6-8], metal hydroxides [9,10], and intumescent flame retardant $[11,12]$ are among the approaches used to improve the fire retardancy of biocomposites. The common fire-retardant mechanisms of WPCs are inherited from the plastic matrix; that is, the nature of the plastic matrix plays an important role in the fire retardancy of biocomposites. Moreover, composites' strength decreases with increasing fire-retardant content due to their hygroscopicity and poor compatibility [13-15]. Hence, it is important to improve the properties of the matrix for the performance of biocomposites.

Interestingly, polycarbonate (PC) has advanced transparency characteristics, dimensional stability, fire resistance, high heat distortion temperature, outstanding impact resistance, and low creep [16,17]. Combining PC and boric-acid-treated wood flour resulted in biocomposites with improved thermal stability [18]. The PC biocomposites showed outstanding mechanical properties comparable to wood and engineered wood products, such as oriented strand board (OSB) and plywood [18]. Cellulose has been filled into PC 
to prepare biocomposites based on engineering plastic [19]. PC combined with cellulose produced highly improved composites (100\% improvement) compared to neat PC [20]. Advantages of wood fibers include low cost, biodegradability, renewability, and low density, making wood-PC composites environmentally friendly [21-23]. Moreover, lignocellulosic fibers improved the biocomposites' fire retardancy compared to neat polymer [24]. Increasing wood flour content improved the biocomposites' flame retardancy. Ignition time, peak heat release rate, and rate of burning decreased, whereas the duration of burning increased [25]. Based on the above findings, wood flour/PC composites are suitable for applications where fire retardancy is essential.

However, lignocellulosic fibers are hydrophilic, increasing the water absorption of the resulting biocomposites. Generally, the mechanical properties of biocomposites decrease after water uptake because water molecules change the structure and properties of fibers, the matrix, and the interface between fibers and polymers [2,26]. Water molecules damage the crystalline structure of lignocellulosic fibers and the polymer chain reorientation. The water uptake process can also affect shrinkage. When the fiber-polymer matrix interface is exposed to moisture, the fibers tend to swell after water absorption, resulting in shear stress development at interfaces, leading to their debonding. The water absorption of polyolefin-based biocomposites increases with the increase in lignocellulosic fiber content [27]. Furthermore, water absorption is closely related to biocomposites' durability and weather resistance [28,29]. Thus, the investigation of water absorption is essential for biocomposites.

Zhang et al. [18] found that wood flour reacted with PC chains through esterification, different from the polyolefin-based WPCs. Esterification will not be observed if the PC is replaced by polyolefin. The compatibility between wood and PC is better than that of wood and polyolefin due to the polar functional groups of PC. Wood flour is evenly distributed in the PC content due to similar polarities [18]. Moreover, a high processing temperature would impact the properties of wood flour, further changing the properties of the composites. This indicates that the structure of wood flour/PC composites is different from that of wood flour/polyolefin composites. Based on the above analysis, it can be summarized that the difference between wood flour/PC composites and wood flour/polyolefin composites is not simply changing the polymer matrix. Thus, it is necessary to explore the fire retardancy and water absorption of the wood flour/PC composites.

Hence, this study explored the effect of borated wood flour content on the fire retardancy and water absorption properties of wood flour/PC composites to promote their application. The fire retardancy of borated wood flour/PC composites was investigated. The microstructure of char layers of wood flour/PC composites explained their fire-retardant mechanism.

\section{Materials and Methods}

\subsection{Materials}

Polycarbonate particles (Makrolon 6485, supplied by Polyone Co., Avon Lake, OH, USA), with a melt flow index of $10 \mathrm{~g} \cdot 10 \mathrm{~min}^{-1}$ (according to ISO $1133,300{ }^{\circ} \mathrm{C}, 1.2 \mathrm{~kg}$ ) and a density of $1.2 \mathrm{~g} \cdot \mathrm{cm}^{-3}$ were used. The pure PC has a fire-retardant grade of UL $94 \mathrm{VO}$. Wood flour (30-80 mesh) was ground from poplar (Populus tremuloides L.) veneers provided by LVL Global, an industrial wood mill in northeast Quebec, Canada. Sigma-Aldrich (Oakville, Canada) provided the boric acid, which is an analytical grade reagent.

\subsection{Preparation of Wood-PC Biocomposites}

Wood flour was treated using a boric acid solution of $5 \mathrm{wt} \%$ by soaking for $2 \mathrm{~h}$. Then, the wood flour was filtered and dried to a moisture content of $2 \%$. The boric acid treatment successfully improved the thermal stability of wood flour [30]. The PC particles were dried at $100{ }^{\circ} \mathrm{C}$ for $10 \mathrm{~h}$ in a laboratory oven. The PC particles and the treated wood flour were extruded at $210^{\circ} \mathrm{C}$ using a HAAKE PolyLab OS Rheodrive (Thermo Electron (Karlsruhe) $\mathrm{GmbH}$, Karlsruhe, Germany) at a speed of $50 \mathrm{rpm}$. The wood flour content varied from 
0 to $40 \mathrm{wt} \%$, as shown in Table 1 . Test samples for mechanical and water absorption were produced using an injection molding machine (MARS II 130/600, Haitian, China). The injection temperature varied from 230 to $245^{\circ} \mathrm{C}$, and the mold temperature was $90{ }^{\circ} \mathrm{C}$. The injection and holding pressures were set at 140 and $70 \mathrm{MPa}$, respectively. The preparation of wood flour/PC composites without boric acid treatment failed due to the degradation of wood flour. Samples for the cone calorimeter (CONE) test were prepared using a hydraulic laboratory press (Fontijne Presses b.v., Vlaardingen, The Netherlands) at a temperature of $230^{\circ} \mathrm{C}$, and a pressure of $20 \mathrm{MPa}$ held for $4 \mathrm{~min}$. Then, samples were cooled down under the same pressure to room temperature.

Table 1. Formulations of the wood flour-PC composites.

\begin{tabular}{cccccc}
\hline Composition & WPCC0 & WPCC10 & WPCC20 & WPCC30 & WPCC40 \\
\hline Wood flour (wt. \%) & 0 & 10 & 20 & 30 & 40 \\
Polycarbonate (wt. \%) & 100 & 90 & 80 & 70 & 60 \\
\hline
\end{tabular}

\subsection{Characterization}

The fire retardancy of the resulting composites was characterized using a cone calorimeter and a vertical burning test. The cone calorimeter tests were carried out according to the ISO 5660-1-2002 standard with a heat flux of $50 \mathrm{~kW} \cdot \mathrm{m}^{-2}$. The cone test measures the heat release rate (HRR), the total heat release (THR), the smoke production rate (SPR), and the total smoke production (TSP). Three replicate samples were tested and averaged for each formulation. Furthermore, a vertical burning test was carried out according to the UL94 standard. Test samples of $80 \times 10 \times 3.2 \mathrm{~mm}^{3}$ were suspended vertically and ignited with a gas flame for 10s, and the total burning time (from ignition to extinction) was recorded. Finally, a KEYENCE 3D microscope (VK-X150K, KEYENCE, Osaka, Japan) was used to analyze the microscopic structure of the composites charring residues after the vertical burning test.

The water absorption test was conducted according to the ASTM D 570 standard. Samples with a diameter of $50 \mathrm{~mm}$ and a thickness of $3.2 \mathrm{~mm}$ were dried at $50{ }^{\circ} \mathrm{C}$ for $24 \mathrm{~h}$ and then placed in distilled water at room temperature. Dimensions were measured using a micrometer with an accuracy of $\pm 0.001 \mathrm{~mm}$, while weights were measured using a laboratory balance with an accuracy of $\pm 0.001 \mathrm{~g}$ at different intervals up to $720 \mathrm{~h}$. We used six replicates for each formulation and measured the thickness at five parallel points for each sample. Furthermore, the two-hour boiling water immersion test was also carried out according to the ASTM D 570 standard. Six replicates with five parallel measurement points were used for each formulation in the boiling water immersion test.

The creep behavior of the wood flour/PC composites was characterized using a thermomechanical analysis instrument (Q400, TA Instruments, New Castle, DE, USA) with a three-point bending mold under a nitrogen atmosphere. Specimens with dimensions of $13 \times 5 \times 1 \mathrm{~mm}$ were loaded at a constant force of $0.1 \mathrm{~N}$ for $600 \mathrm{~s}$ at $50{ }^{\circ} \mathrm{C}$.

The resulting composites' creep curves were fitted by the Burgers and Findley's models to analyze their viscoelasticity using the Origin 2017 (OriginPro 2017, OriginLab, Northampton, MA, USA) software. The Burgers model, consisting of one Maxwell element and one Kelvin-Voigt element connected in series, is described by Equation (1) [31]:

$$
\varepsilon=\frac{\sigma}{E_{1}}+\frac{\sigma}{E_{2}}\left(1-\exp \left(-t \frac{E_{2}}{\eta_{2}}\right)\right)+t \frac{\sigma}{\eta_{1}}
$$

where $\varepsilon$ is the total strain accumulated after the time $t$ after the stress $\sigma$ is applied. $E_{1}$ and $E_{2}$ represent the modulus of elasticity of the springs in the Maxwell and Kelvin-Voigt units, respectively. $\eta_{1}$ and $\eta_{2}$ are the corresponding damping viscosities. Equation (2) describes Findley's model:

$$
\varepsilon(t)=\varepsilon_{0}+A t^{n}
$$


where $\varepsilon(t)$ is the time-dependent creep strain, while $\varepsilon_{0}$ is the instantaneous elastic strain. $A$ is the magnitude of the transient creep strain, and $n$ is a constant.

\section{Results and Discussion}

\subsection{Fire Retardancy}

Figures 1 and 2 and Table 2 show the fire retardancy parameters of the wood-PC composites. These parameters include HRR, the peak of HRR (PHRR), total heat release, total smoke release, ignition time (IT), mass loss rate (MLR), and flaming dripping. IT (Table 2), HRR (Figure 1), and PHRR (Table 2) decreased with increasing wood flour proportion. Compared to PC, the lower thermal stability of wood flour can explain this result $[18,19]$. The changes in IT were rather marginal, which is consistent with the previous study [32]. The effect of wood flour content on IT is not obvious. Although a limiting oxygen index (LOI) test may help differentiate the effect of wood content, the previous literature cautioned against using the LOI to measure the flammability of WPC. In a real fire situation, factors such as lower oxygen accessibility and higher air velocity and temperature can influence the LOI of the composites [33]. The HRR of the resulting composites decreased gradually with increasing wood flour content (Figure 1b). The PRHH of composites fell from $332.3 \mathrm{~kW} \mathrm{~m}^{-2}$ for neat PC to $187.9 \mathrm{~kW} \mathrm{~m}^{-2}$ for WPC40. The heat release rate decreased by $43.5 \%$. The THR also reduced with the increase in wood flour content. The previous literature reported similar findings [34,35]. The decrease in heat release rate can be explained by the fact that the burning heat of wood flour is lower than that of polymers due to its high oxygen element content [36]. The slope of the THR curve is representative of flame spread. Hence, adding wood flour decreased the flame spread of the resulting composites, as shown in Figure $1 \mathrm{~b}$. Similar to HRR, the SPR gradually reduced with increasing wood flour content (Figure 1c), and the TSP curves in Figure 1d show similar results. The degradation of wood flour produced char layers, playing a crucial role in smoke suppression [37].


Figure 1. Heat rate release (HRR) (a), total heat release (THR); (b), smoke production rate (SPR); (c), total smoke production (TSP); (d), and curves of wood-PC composites. 

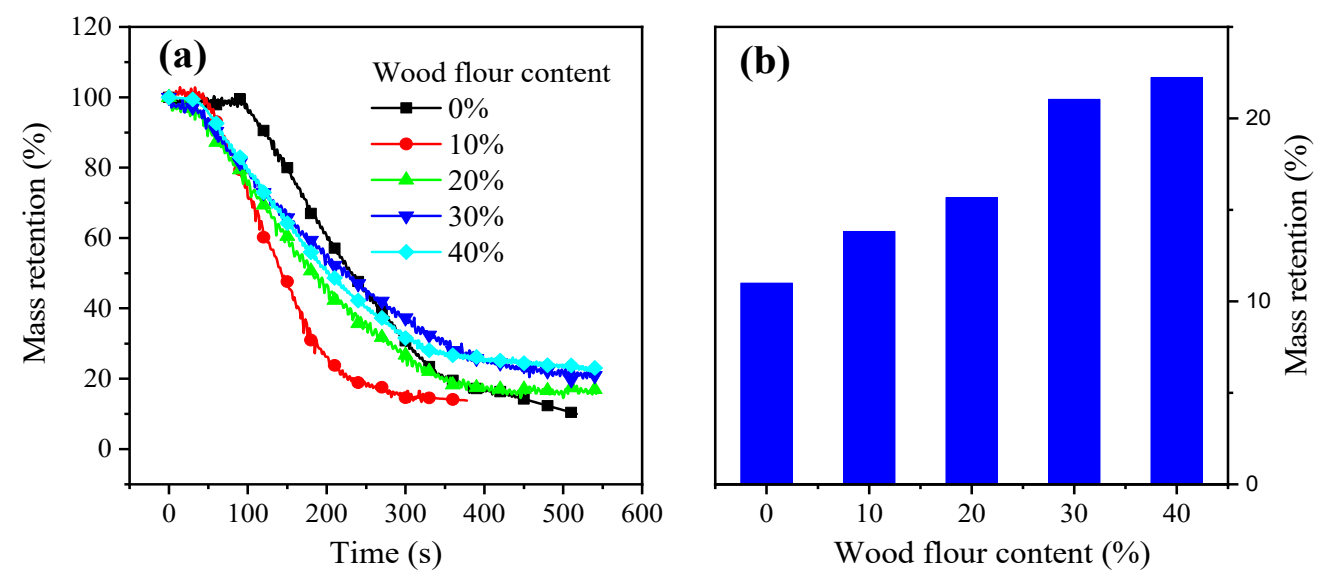

Figure 2. Mass retention curves of wood flour/PC composites (a) and the mass residue of the resulting composites at $500 \mathrm{~s}(\mathbf{b})$.

Table 2. Combustion parameters of wood flour/PC composites.

\begin{tabular}{ccccc}
\hline Samples & IT (s) & PHRR $\left(\mathbf{k W} \mathbf{~}^{-\mathbf{2}}\right)$ & Flaming Dripping & Self-Extinguishing \\
\hline Neat PC & 88 & 332.3 & No & Yes \\
WPC10 & 28 & 298.3 & No & Yes \\
WPC20 & 31 & 216.3 & No & Yes \\
WPC30 & 31 & 182.8 & No & Yes \\
WPC40 & 32 & 187.9 & No & Yes \\
\hline
\end{tabular}

Moreover, the mass fraction of residue of the resulting composites quickly decreased with the irradiation time after ignition. After approximately $400 \mathrm{~s}$, the mass retention curves tended to level off. However, the combustion of composites with $10 \%$ wood flour content was short. HRR and SPR curves show similar trends. This may be due to the fact that the wood flour content is too low to form a protective char layer, and the thermal stability of the wood flour is lower than PC. The residues rate at $500 \mathrm{~s}$ increased by $102.27 \%$ from $10.99 \%$ of neat PC to $22.23 \%$ of WPC40 (Figure 2). Mass retention can be attributed to the suppressing effect on the flame combustion, accumulating more char during the combustion. Moreover, the vertical burning test did not show any flaming dripping for all tested samples during combustion. Additionally, a self-extinguishing phenomenon was observed for all samples (Table 2). Neat PC is self-extinguishing, whereas wood flour is the opposite [36]. In summary, wood flour and PC have a synergistic effect on fire retardancy in the wood-PC composites.

\subsection{Morphological Characterization}

The digital photos of wood-PC composites, neat PC, and WPC10 showed evident inflation after the CONE test. This is because PC degradation produced a large amount of carbon dioxide $\left(\mathrm{CO}_{2}\right)$ [38]. Meanwhile, the vaporized $\mathrm{CO}_{2}$ could also dilute the flammable gases and oxygen during burning, acting as gas-phase fire retardancy. Hence, the pure PC is self-extinguishing after the removal of the fire resource. However, the inflation of the char residue decreased when the content of wood flour was more than $20 \%$. Additionally, the surface of the residual carbon became flat (Figure 3). Wood flour degraded and formed char layers, suppressing the overflow of volatile gases and burning the composites. Furthermore, the foamed char reduced the thermal conductivity at the material interior, enhancing the fire retardancy of wood flour/PC composite, which was in accord with the above CONE analysis results.

The morphology of the char layers measured by a laser microscope revealed that the char of pure PC seemed smooth and dense (Figure 4a). A uniform porous carbon framework of char after combustion was also observed (Figure 4b). With the addition of wood flour, an inhomogeneous and relatively loose structure with many flaws appeared on the surface of the char layer. Wood flour formed this loose char structure. Hence, 
the biochar can prevent heat and flammable gases from penetrating the PC. The biochar increased with increasing wood flour content in composites (Figure 4).



Figure 3. (a) Digital photos of char formation for wood-PC composites after cone calorimeter and the surface morphology of char formed from the resulting composites with different wood contents: (b) $0 \%$; (c) $10 \%$; (d) $20 \%$, (e) $30 \%$ and (f) $40 \%$.



Figure 4. Micromorphology of char formation for wood-PC composites with different wood flour contents after vertical burning test: (a,b) $0 \%$, (c) 10\%, (d) 20\%, (e) 30\%, and (f) $40 \%$. 


\subsection{Water Absorption}

Figure 5 shows that the water absorption and the thickness swelling of the wood flour/PC composites increased with time and increased wood flour content. The water absorption of composites with $40 \%$ wood flour content is about 5.3 times more than pure PC. The wood flour has many free hydroxyl groups on its surface, leading to water absorption [39]. However, the hydrophobic PC matrix is considered the nonabsorbent part of the biocomposites. When immersing the biocomposites in water, the free hydroxyl groups of wood flour formed hydrogen bonds with water molecules [40]. An increasing number of hydroxyl groups of wood flour appeared on the surface of the biocomposites with increasing wood flour content, increasing water uptake. The previous literature reported a similar phenomenon for both wood polypropylene composites and wood HDPE composites [41,42]. For the two-hour boiling water test, the water absorption of the biocomposites did not change obviously with increasing wood flour content. This indicates the excellent hydrothermal stability of the composites. Moreover, the trend of the thickness swelling of the biocomposites in the boiling water test was similar to that in the water absorption test at room temperature. Upon immersion, wood flour on the surface of composites uptakes water and swell; then, the water is transferred from one cell to another over time [39].


Figure 5. Water absorption (a) and thickness swelling (b) of wood-PC composites at room temperature, and water absorption (c) and thickness swelling (d) in two-hour boiling water test.

\subsection{Creep Properties}

Creep is an important property for composites since it is indicative of the potential structural applications. Wood content, polymer nature, wood particle size, test time, temperature, applied stress, and humidity influence the creep behavior of biocomposites. Generally, the creep behavior is more severe for biocomposites than for wood due to the nature of polymers [43]. In the current study, the creep strain of the wood-PC composites 
decreased with higher wood flour content (Figure 6), in good agreement with previous findings for wood-polypropylene composites [44]. The reason for this may be that wood flour restricted the stretching, bending, and slipping of PC molecular chains, which is in good agreement with the modulus results of the composites [18]. Furthermore, the rigidity of wood flour is higher than that of pure PC plastic, which increases the anti-creep property of the resulting wood flour-PC composites $[40,45]$.

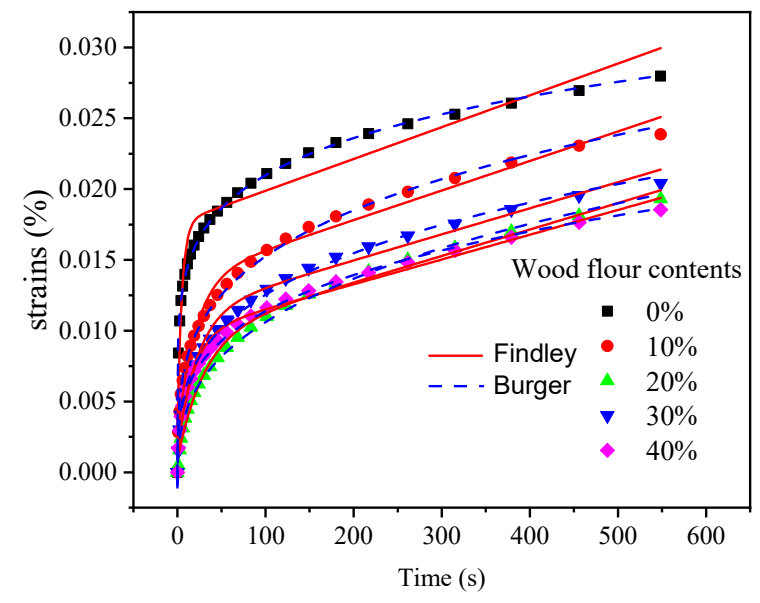

Figure 6. Creep behavior of wood-PC composites.

Creep occurs due to the viscoelastic deformation of the biocomposites, including elastic deformation and viscous flow. Hence, the Burgers and Findley's models analyzed the composites' viscoelastic (creep) performance [30]. Compared to the Burgers model, Findley's power law model produced a better fit to the data, as shown in Figure 6 and Table 3. Generally, the Burgers model describes the entire creep process well, including instantaneous deformation, viscoelastic deformation, and viscous deformation. The viscoelastic deformation usually occurs in the early stage of creep behavior caused by molecular chain relaxations and extensions. In contrast, the viscous part is the long-term creep strain attributed to the slippage of molecular chains [46]. However, the resulting composites did not contain all three phases for the short-term creep test in this study, especially not the total viscoelastic stage. This explains why the Burgers model did not entirely fit the short-term experimental data. Findley's power law model fitted the experimental data well. It does not clearly distinguish the two parts of the second stage and does not represent well the viscosity stage. Therefore, it may be more suitable to fit only short-term creep data. The results were in good agreement with the previous literature [43,47].

Table 3. Parameters of Burgers model and Findley's power law model.

\begin{tabular}{|c|c|c|c|c|c|c|c|c|c|}
\hline \multirow[b]{2}{*}{ Wood Flour Content } & \multicolumn{4}{|c|}{ Burgers Model } & \multicolumn{5}{|c|}{ Findley's Power Law Model } \\
\hline & $\mathrm{E}_{1}(\mathrm{MPa})$ & $\mathrm{E}_{2}(\mathrm{MPa})$ & $\eta_{1}$ (MPa s) & $\eta_{2}$ (MPa s) & $\mathbf{R}^{2}$ & $\varepsilon_{0}$ & A & $n$ & $\mathbf{R}^{2}$ \\
\hline $0 \%$ & 6391.482 & 1378.851 & $890,473.587$ & 6951.743 & 1.00 & $-6.4998 \times 10^{-4}$ & 0.00336 & 0.27717 & 0.995 \\
\hline $10 \%$ & 8158.469 & 1787.585 & $958,608.082$ & $36,341.878$ & 1.00 & $-1.09 \times 10^{-3}$ & 0.00248 & 0.33628 & 0.995 \\
\hline $20 \%$ & $11,716.722$ & 2089.627 & $1,086,001.610$ & $48,037.217$ & 1.00 & $-9.1809 \times 10^{-4}$ & 0.00363 & 0.2847 & 0.995 \\
\hline $30 \%$ & $21,637.338$ & 2286.305 & $1,070,591.423$ & $70,117.161$ & 1.00 & $-8.4842 \times 10^{-4}$ & 0.00474 & 0.26555 & 0.996 \\
\hline $40 \%$ & $13,531.938$ & 2410.191 & $1,142,779.012$ & $43,057.373$ & 1.00 & $-2.2283 \times 10^{-4}$ & 0.00977 & 0.16832 & 0.998 \\
\hline
\end{tabular}

\section{Conclusions}

In this study, we prepared wood flour/PC composites using injection molding by improving the thermal stability of the wood flour with boric acid and explored the effect of wood flour content on their fire retardancy, water absorption, and creep properties. The results indicate that the wood flour/PC composites had good fire retardancy and were selfextinguishing. Furthermore, the cone calorimeter test parameters, namely, HRR, THR, SPR, and TSP, decreased with increasing wood flour content. However, the water absorption of 
the composites increased with an increase in wood flour content. Moreover, the creep of the resulting composites decreased with increasing wood flour content. Adding wood flour reduced the cost of PC composites. It improved the fire retardancy and anti-creep properties of the resulting composites. Expanding the use field of biocomposites and promoting their technological development are among the practical implications of this study.

Author Contributions: J.Z:: Conceptualization, Methodology, Investigation, Writing, Review, and Editing; A.K.: Supervision, Conceptualization, Methodology, Funding Acquisition, Writing, Review, and Editing; D.X.: Data Curation; F.G.: Methodology, Review, and Editing; P.L.: Review and Editing; Y.T.: Review and Editing; X.-M.W.: Supervision, Validation, Review, and Editing; H.W.: Supervision, Validation, Reviewing, and Editing. All authors have read and agreed to the published version of the manuscript.

Funding: This research was funded by the Canada Research Chair Program, grant number 557752, NSERC Grant number 494346-16.

Institutional Review Board Statement: Not applicable.

Informed Consent Statement: Not applicable.

Data Availability Statement: The data presented in this study are available on request from the corresponding author. The data are not publicly available because they are still being used for modeling work.

Acknowledgments: The authors thank Gilles Villeneuve and Williams Belhadef for technical assistance.

Conflicts of Interest: The authors declare no conflict of interest.

\section{References}

1. Zhao, P.; Guo, C.; Li, L. Exploring the effect of melamine pyrophosphate and aluminum hypophosphite on flame retardant wood flour/polypropylene composites. Constr. Build. Mater. 2018, 170, 193-199. [CrossRef]

2. Kaboorani, A. Characterizing water sorption and diffusion properties of wood/plastic composites as a function of formulation design. Constr. Build. Mater. 2017, 136, 164-172. [CrossRef]

3. Lopez, Y.M.; Paes, J.B.; Gustave, D.; Gonçalves, F.G.; Méndez, F.C.; Nantet, A.C.T. Production of wood-plastic composites using cedrela odorata sawdust waste and recycled thermoplastics mixture from post-consumer products-A sustainable approach for cleaner production in Cuba. J. Clean. Prod. 2020, 244, 118723. [CrossRef]

4. Sain, M. Market and product opportunities for WPCs/NFPCs beyond building industry. In Proceedings of the 9th International Conference on Wood and Biofiber Plastic Composites, Plenary Session, Madison, WI, USA, 21-23 May 2007.

5. Research, G.V. Wood Plastic Composite Market Analysis Report by Type (Polyethylene, Polypropylene, Polyvinylchloride), By Application (Automotive, Construction, Industrial \& Consumer Goods), and Segment Forecasts, 2018-2025; Grand View Research: San Francisco, CA, USA, 2018.

6. Sun, Y.; Yuan, B.; Shang, S.; Zhang, H.; Shi, Y.; Yu, B.; Qi, C.; Dong, H.; Chen, X.; Yang, X. Surface modification of ammonium polyphosphate by supramolecular assembly for enhancing fire safety properties of polypropylene. Compos. Part B Eng. 2020, 181, 107588. [CrossRef]

7. Turku, I.; Kärki, T. Accelerated weathering of fire-retarded wood-polypropylene composites. Compos. Part A Appl. Sci. Manuf. 2016, 81, 305-312. [CrossRef]

8. Ding, C.; Pan, M.; Chen, H.; Zhang, S.; Mei, C. An anionic polyelectrolyte hybrid for wood-polyethylene composites with high strength and fire safety via self-assembly. Constr. Build. Mater. 2020, 248, 118661. [CrossRef]

9. Zhang, J; Wu, Q.; Li, G.; Li, M.-C.; Sun, X.; Ring, D. Synergistic influence of halogenated flame retardants and nanoclay on flame performance of high density polyethylene and wood flour composites. RSC Adv. 2017, 7, 24895-24902. [CrossRef]

10. Li, M.; Zhang, Z.; Wu, L.; Zhang, Y.; Mai, K. $\beta$-Crystallization and mechanical properties of aluminum hydroxide-filled poly-propylene composites. Polym. Compos. 2019, 40, E194-E201. [CrossRef]

11. Guan, Y.-H.; Liao, W.; Xu, Z.-Z.; Chen, M.-J.; Huang, J.-Q.; Wang, Y.-Z. Improvement of the flame retardancy of woodfibre/polypropylene composites with ideal mechanical properties by a novel intumescent flame retardant system. RSC Adv. 2015, 5, 59865-59873. [CrossRef]

12. Zhang, L.; Chen, S.; Pan, Y.-T.; Zhang, S.; Nie, S.; Wei, P.; Zhang, X.; Wang, R.; Wang, D.-Y. Nickel Metal-Organic Framework Derived Hierarchically Mesoporous Nickel Phosphate toward Smoke Suppression and Mechanical Enhancement of Intu-mescent Flame Retardant Wood Fiber/Poly (lactic acid) Composites. ACS Sustain. Chem. Eng. 2019, 7, 9272-9280. [CrossRef]

13. Kalali, E.N.; Zhang, L.; Shabestari, M.E.; Croyal, J.; Wang, D.-Y. Flame-retardant wood polymer composites (WPCs) as potential fire safe bio-based materials for building products: Preparation, flammability and mechanical properties. Fire Saf. J. 2019, 107, 210-216. [CrossRef] 
14. Yu, F.; Xu, F.; Song, Y.; Fang, Y.; Zhang, Z.; Wang, Q.; Wang, F. Expandable graphite's versatility and synergy with carbon black and ammonium polyphosphate in improving antistatic and fire-retardant properties of wood flour/polypropylene composites. Polym. Compos. 2017, 38, 767-773. [CrossRef]

15. Schirp, A.; Hellmann, A. Fire retardancy improvement of high-density polyethylene composites based on thermomechanical pulp treated with ammonium polyphosphate. Polym. Compos. 2019, 40, 2410-2423. [CrossRef]

16. Nishino, K.; Shindo, Y.; Ito, H.; Takayama, T. Improvement of impact strength and hydrolytic stability of PC/ABS blend using reactive polymer. J. Appl. Polym. Sci. 2016, 134. [CrossRef]

17. Wang, X.; Zhang, W.; Qin, Z.; Yang, R. Optically transparent and flame-retarded polycarbonate nanocomposite based on diphenylphosphine oxide-containing polyhedral oligomeric silsesquioxanes. Compos. Part A Appl. Sci. Manuf. 2019, 117, 92-102. [CrossRef]

18. Zhang, J.; Koubaa, A.; Xing, D.; Liu, W.; Wang, H.; Wang, X.; Wang, Q. High-performance lignocellulose/polycarbonate bio-composites fabricated by in situ reaction: Structure and properties. Compos. Part A Appl. Sci. Manuf. 2020, 138, 106068. [CrossRef]

19. Mariano, M.; El Kissi, N.; Dufresne, A. Melt processing of cellulose nanocrystal reinforced polycarbonate from a masterbatch process. Eur. Polym. J. 2015, 69, 208-223. [CrossRef]

20. Panthapulakkal, S.; Sain, M. Preparation and characterization of cellulose nanofibril films from wood fibre and their thermoplastic polycarbonate composites. Int. J. Polym. Sci. 2012, 2012, 381342. [CrossRef]

21. Liu, Y.; Li, G.; Hu, Y.; Wang, A.; Lu, F.; Zou, J.-J.; Cong, Y.; Li, N.; Zhang, T. Integrated Conversion of Cellulose to High-Density Aviation Fuel. Joule 2019, 3, 1028-1036. [CrossRef]

22. Zhang, J.; Li, Y.; Xing, D.; Wang, Q.; Wang, H.; Koubaa, A. Reinforcement of continuous fibers for extruded wood-flour/HDPE composites: Effects of fiber type and amount. Constr. Build. Mater. 2019, 228, 116718. [CrossRef]

23. Zaaba, N.F.; Malaysia, M.U.S.; Ismail, H. Thermoplastic/Natural Filler Composites: A Short Review. J. Phys. Sci. 2019, 30, 81-99. [CrossRef]

24. Kandola, B.K.; Mistik, S.I.; Pornwannachai, W.; Anand, S.C. Natural fibre-reinforced thermoplastic composites from wo-vennonwoven textile preforms: Mechanical and fire performance study. Compos. Part B 2018, 153, 456-464. [CrossRef]

25. Kandola, B.K.; Pornwannachai, W.; Ebdon, J.R. Flax/PP and Flax/PLA Thermoplastic Composites: Influence of Fire Retardants on the Individual Components. Polymers 2020, 12, 2452. [CrossRef] [PubMed]

26. Hyvärinen, M.; Ronkanen, M.; Kärki, T. The effect of the use of construction and demolition waste on the mechanical and moisture properties of a wood-plastic composite. Compos. Struct. 2019, 210, 321-326. [CrossRef]

27. Chun, K.S.; Fahamy, N.M.Y.; Yeng, C.Y.; Choo, H.L.; Ming, P.M.; Thai, K.Y. Wood-plastic composites made from corn husk fiber and recycled polystyrene foam. J. Eng. Sci. Technol. 2018, 13, 3445-3456.

28. Feng, J.; Li, S.; Peng, R.; Sun, T.; Xie, X.; Shi, Q. Effects of fungal decay on properties of mechanical, chemical, and water absorption of wood plastic composites. J. Appl. Polym. Sci. 2021, 138, 50022. [CrossRef]

29. Kamau-Devers, K.; Kortum, Z.; Miller, S.A. Hydrothermal aging of bio-based poly (lactic acid) (PLA) wood polymer compo-sites: Studies on sorption behavior, morphology, and heat conductance. Constr. Build. Mater. 2019, 214, 290-302. [CrossRef]

30. Zhang, J.; Koubaa, A.; Xing, D.; Wang, H.; Wang, Y.; Liu, W.; Zhang, Z.; Wang, X.; Wang, Q. Conversion of lignocellulose into biochar and furfural through boron complexation and esterification reactions. Bioresour. Technol. 2020, 312, 123586. [CrossRef] [PubMed]

31. Wu, C.M.; Lin, P.C.; Murakami, R. Long-term creep behavior of self-reinforced PET composites. Express Polym. Lett. 2017, 11, 820-831. [CrossRef]

32. Stark, N.M.; Mueller, S.A.; White, R.H.; Osswald, T.A. Effect of fire retardants on heat release rate of wood flour-polyethylene composites. In Proceedings of the 10th International Conference on Wood \& Biofiber Plastic Composite and Cellulose Nanocomposites Symposium, Madison, WI, USA, 11-12 May 2009; pp. 103-109.

33. Chapple, S.; Anandjiwala, R. Flammability of Natural Fiber-reinforced Composites and Strategies for Fire Retardancy: A Review. J. Thermoplast. Compos. Mater. 2010, 23, 871-893. [CrossRef]

34. Kozłowski, R.; Władyka-Przybylak, M. Flammability and fire resistance of composites reinforced by natural fibers. Polym. Adv. Technol. 2008, 19, 446-453. [CrossRef]

35. Nikolaeva, M.; Kärki, T.I.M.O. A review of fire retardant processes and chemistry, with discussion of the case of wood-plastic composites. Baltic For 2011, 17, 314326.

36. Grand, A.F.; Wilkie, C.A. Fire Retardancy of Polymeric Materials; CRC Press: Boca Raton, FL, USA, 2000.

37. Sun, L.; Xie, Y.; Ou, R.; Guo, C.; Hao, X.; Wu, Q.; Wang, Q. The influence of double-layered distribution of fire retardants on the fire retardancy and mechanical properties of wood fiber polypropylene composites. Constr. Build. Mater. 2020, $242,118047$. [CrossRef]

38. Navarro-Gonzalez, R.; Coll, P.; Aliev, R. Pyrolysis of $\gamma$-irradiated bisphenol-A polycarbonate. Polym. Bull. 2002, 48, 43-51. [CrossRef]

39. Mu, B.; Wang, H.; Hao, X.; Wang, Q. Morphology, Mechanical Properties and Dimensional Stability of Biomass Particles/High Density Polyethylene Composites: Effect of Species and Composition. Polymers 2018, 10, 308. [CrossRef] [PubMed]

40. Azeh, Y.; Olatunji, G.A.; Mamza, P.A. Scanning Electron Microscopy and Kinetic Studies of Ketene-Acetylated Wood/Cellulose High-Density Polyethylene Blends. Int. J. Carbohydr. Chem. 2012, 29, 1-7. [CrossRef] 
41. Benthien, J.T.; Ohlmeyer, M. Thickness swelling and water absorption of WPC after immersion in cold and boiling water. Eur. J. Wood Wood Prod. 2013, 71, 437-442. [CrossRef]

42. Feng, J.; Shi, Q.; Chen, Y.; Huang, X. Mold Resistance and Water Absorption of Wood/HDPE and Bamboo/HDPE Composites. J. Appl. Sci. 2014, 14, 776-783. [CrossRef]

43. Wang, W.-H.; Huang, H.-B.; Du, H.-H.; Wang, H. Effects of fiber size on short-term creep behavior of wood fiber/HDPE composites. Polym. Eng. Sci. 2014, 55, 693-700. [CrossRef]

44. Lee, S.-Y.; Yang, H.-S.; Kim, H.-J.; Jeong, C.-S.; Lim, B.-S.; Lee, J.-N. Creep behavior and manufacturing parameters of wood flour filled polypropylene composites. Compos. Struct. 2004, 65, 459-469. [CrossRef]

45. The Engineering ToolBox. Young's Modulus-Tensile and Yield Strength for Common Materials. Engineering ToolBox United States, 2003. Available online: https:/ / www.engineeringtoolbox.com/young-modulus-d_417.html (accessed on 22 May 2021).

46. Rimdusit, S.; Wongsongyot, S.; Jittarom, S.; Suwanmala, P.; Tiptipakorn, S. Effects of gamma irradiation with and without compatibilizer on the mechanical properties of polypropylene/wood flour composites. J. Polym. Res. 2011, 18, 801-809. [CrossRef]

47. Bouafif, H.; Koubaa, A.; Perré, P.; Cloutier, A. Creep behaviour of HDPE/wood particle composites. Int. J. Microstruct. Mater. Prop. 2013, 8, 225-238. [CrossRef] 